\title{
ХИРУРГИЧЕСКОЕ ЛЕЧЕНИЕ ЗОБА БОЛЬШИХ РАЗМЕРОВ НА ФОНЕ СИНДРОМА ОСТРОЙ ДЫХАТЕЛЬНОЙ НЕДОСТАТОЧНОСТИ
}

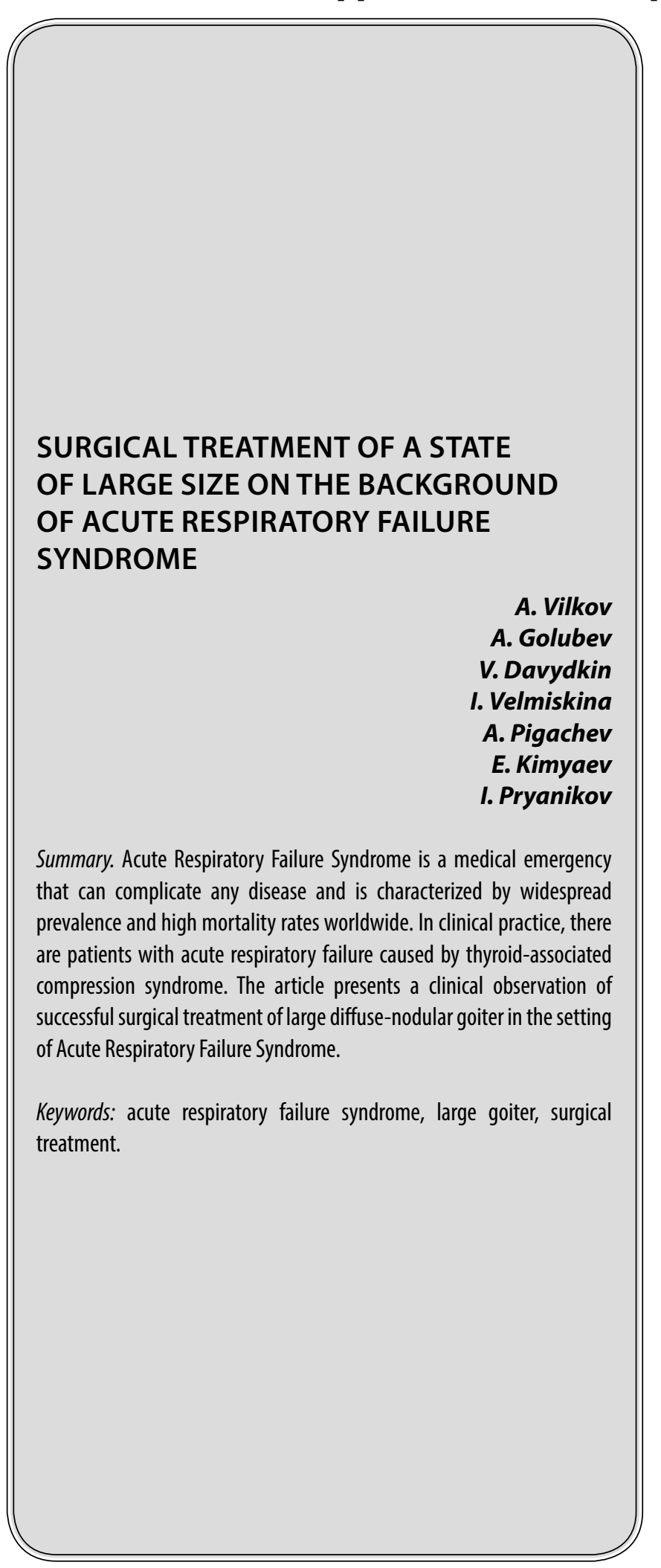

Вилков Александр Владимирович

К.м.н., дочент, Национальный исследовательский Мордовский государственный университет им. Н.П. Огарёва vilkov_a_v@mail.ru

Голубев Александр Григорьевич

К.м.н., дочент, Национальный исследовательский Мордовский государственный университет

Давыдкин Василий Иванович

К.м.н., дочент, Национальный исследовательский Мордовский государственный университет им. Н.П. Огарёва

Вельмискина Ирина Васильевна К.м.н., дочент, Национальный исследовательский Мордовский государственный университет им. Н.П. Огарёва

Пигачев Андрей Вениаминович

К.м.н., доцент, Национальный исследовательский Мордовский государственный университет им. Н.П. Огарёва

Кимяев Евгений Викторович

Ассистент, Национальный исследовательский Мордовский государственный университет им. Н.П. Огарёва

Пряников Ильдар Ринатович

Аспирант, Национальный исследовательский Мордовский государственный университет им. Н.П. Огарёва

Аннотация. Синдром острой дыхательной недостаточности (ОДН) - это неотложное состояние, которое может осложнять любое заболевание и характеризуется широкой распространенностью и высоким уровнем летальности во всем мире. В клинической практике появляются пациенты с острой дыхательной недостаточностью, вызванной тиреоид-ассоциированным компрессионным синдромом. В работе приведено клиническое наблюдение успешного хирургического лечения диффузно-узлового зоба больших размеров на фоне синдрома ОДН.

Ключевые слова: синдром острой дыхательной недостаточности, $30 б$ больших размеров, хирургическое лечение. 


\section{Актуальность}

индром острой дыхательной недостаточности (ОДН) - это неотложное состояние, которое может осложнять любое заболевание и характеризуется широкой распространенностью и высоким уровнем летальности во всем мире [2].

Поскольку в отечественной литературе существует дефицит совокупных данных по эпидемиологии ОДН [1], сведения, полученные за рубежом, в целом свидетельствуют об увеличении распространенности этого синдрома [3].

На территории США за 9 лет численность пациентов, госпитализированных с диагнозом ОДН, возросла почти вдвое [2].

Полиэтиологический характер и высокая распространенность синдрома ОДН оставляют его на одном из первых мест в глобальной структуре смертности [4]. В клинической практике появляются пациенты с острой дыхательной недостаточностью, вызванной тиреоид-ассоциированным компрессионным синдромом. Учитывая широкую распространенность синдрома и высокий уровень летальности пациентов с ОДН, большое значение имеет умение врача своевременно выявить нарушения функции дыхания, провести надлежащую неотложную коррекцию дыхательных расстройств и тем самым предупредить развитие смертельного исхода [2].

\section{Цель исследования}

Продемонстрировать клиническое наблюдение успешного хирургического лечения диффузно-узлового зоба больших размеров на фоне синдрома ОДН.

\section{Клиническое наблюАение}

Больная Л., 71 года, доставлена бригадой врачей СМП в дежурную больницу после звонка соседей о ее неадекватном поведении с диагнозом: Тромбоэмболия легочной артерии? Активных жалоб не предъявляет. Осмотру сопротивляется. На вопросы не отвечает. Подробный анамнез собрать не предоставляется возможным. Со слов родственников, у эндокринолога больная не наблюдалась, лечение не получала. Госпитализирована в отделение реанимации.

\section{При объективном осмотре}

Общее состояние тяжелое. В сознании, возбуждена. Критика к собственному состоянию отсутствует. Сатурация $\mathrm{O}_{2}$ не определяется. Кожные покровы бледные с акроцианозом, влажные. Телосложение правильное. Конституция нормостеническая. Положение лежа на каталке. Грудная клетка конической формы. Над легкими жесткое дыхание, ослабленное в нижних отделах, рассеянные сухие и влажные хрипы, с ЧД-28 в/мин. Область сердца не изменена. Тоны сердца приглушены, ритм правильный с чСС-100/мин. АД-130/80мм рт. ст. Перкуторно границы сердца не смещены, не расширены. Язык чистый, влажный. Живот не вздут, симметричный, участвует в акте дыхания. Пальпаторно мягкий, безболезненный. Локально: щитовидная железа значительно увеличена (II степень по ВОЗ). Пальпаторно в обеих долях железы - множественные узловые образования до 10,0 см, спаянные с окружающими тканями, безболезненные, плотно-эластической консистенции. Тремора, экзофтальма и глазных симптомов не выявлеHO.

Результаты лабораторных и инструментальных методов исследования:

Общий анализ крови: Лейкоциты-8,1*10/9/л; Hb-131г/л; эритроциты-4,7*10/12/л. Ht-40\%; Тромбоциты $-239 * 10 / *$ /л.; СОЭ-12мм/ч.

Общий анализ мочи: уд. вес-1018, цвет-желт.; белок-0,169, эр.-5-8в п.зр. Лейк.- 10-12 в п.зр.

Биохимический анализ крови: Билирубин- общий -10,72 ммоль/л, непрямой-10,72. АЛТ-41 Ед/л, АСТ-82Ед/л, а-амилаза -53мг; мочевина-9,5 ммоль/л, креатинин-0,100 моль/л, общий белок -74г/л. сахар крови-7,0 ммоль/л

Коагулограмма: АЧТВ-23, МНО-1,25, ПТИ-86, Фибриноген-3500

ЭКГ: Ритм синусовый с ЧСС-100/мин. ЭОС не отклонена. Блокада правой ножки пучка Гиса.

Рентгенограмма органов грудной клетки: Правосторонняя нижнедолевая полисегментарная пневмония. Диффузный пневмосклероз.

УЗИ ЩЖ: щитовидная железа значительно увеличена в размерах за счет обеих долей и перешейка, правая доля 90*60*92мм; левая $-110^{*} 66^{*} 100$ мм, контуры четкие, ровные, перешеек 3,5 см, структура неоднородная, нормэхогенная со множественными узловыми образованиями до 4 см с кистозным компонентом и кальцинатами. Общий объем щитовидной железы - 583 мл 3 .

Гормоны щзитовидной железы: свободный трийодтиронин-2,57, свободный тироксин-7,69, ТТГ-0,98, АТ к ТПО-0,98. 


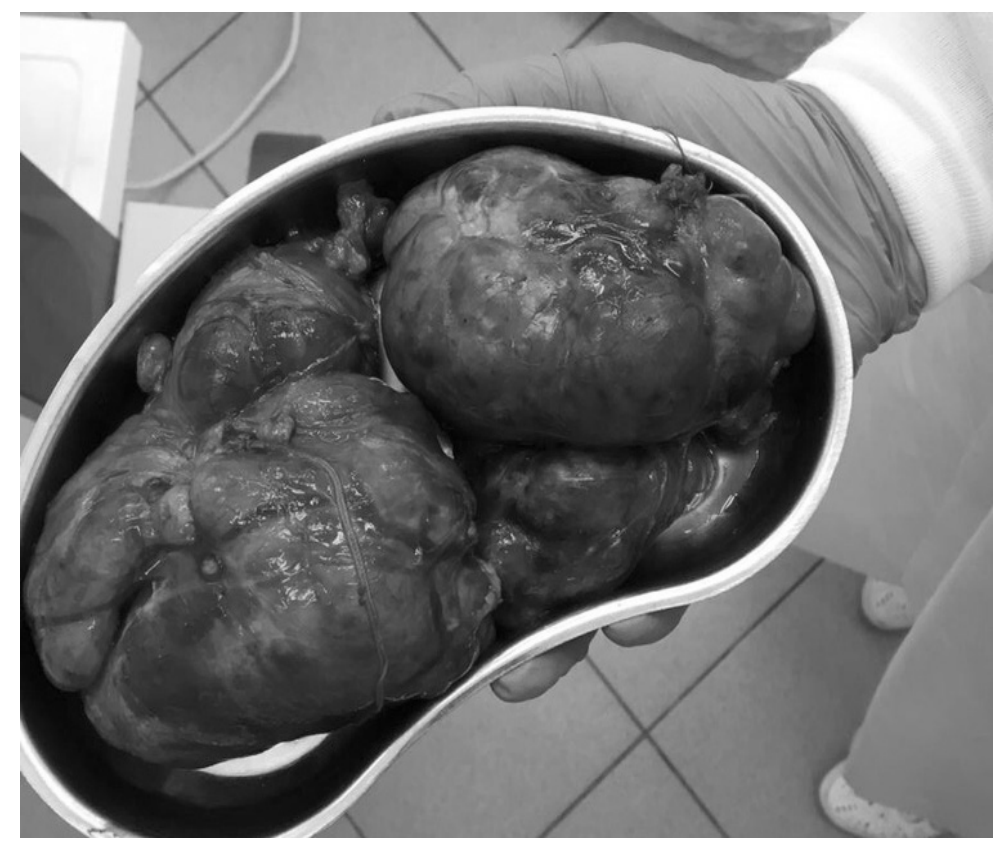

Рис.1. Макропрепарат удаленной щитовидной железы

Исследование крови на онкомаркерь: СА-12584,23Ед/мл. СА-19.9-20,67 Ед/мл. СА 15,3-30,41 Ед/мл. Раково-эмбриональный антиген-0,81 нг/мл.

КT органов грудной полости: КТ-признаки правосторонней полисегментарной нижнедолевой пневмонии, внутригрудной лимфоаденопатии. Щитовидная железа увеличена в размерах за счет наличия многоузлового объемного образования с четкими бугристыми контурами (правая доля -86*54*92мм; левая-103*66*101мм), структура неоднородная с наличием микро- и макрокальцинатов. Узловое образование распространяется каудально в верхний этаж средостения до уровня дуги аорты, несколько деформируя ее контур. Образование выраженно деформирует и суживает просвет трахеи до 9 мм и компрессирует прилежащие структуры мягких тканей шеи, общие сонные артерии и вены смещены кзади без убедительных признаков сужения их просвета.

Пункция узловых образований ЩЖ: Диффузно-узловой макрофолликулярный коллоидный зоб.

Фибробронхоскопия: Сужение и деформация верхней и средней третей трахеи (сдавление извне)

Осмотр невролога: Дисциркуляторная (атеросклеротическая, гипоксическая) энцефалопатия III степени смешанного генеза.

Осмотр эндокринолога: Диффузно-узловой зоб ॥ ст. Эутиреоидная форма.
Ocмотр хирурга: Диффузно-узловой зоб II ст. с компрессионным синдромом. Эутиреоидная форма.

Ocмотр терапевта: Внегоспитальная правосторонняя нижнедлевая пневмония тяжелое течение. ДН ІІІ.

\section{Обсу»кение}

Учитывая тяжесть состояния, обусловленную явлениями нарастающей дыхательной недостаточности, возраст и результаты лабораторно-инструментальных методов обследований было принято решение о госпитализации пациентки в отделение реанимации, где проводилась антибактериальная терапия, антикоагулянтная терапия, гастропротективная, бронхолитическая и муколитическая терапия. Отмечается, что при инсуфляции увлажненного кислорода через назальный катетер, явления дыхательной недостаточности не купируются, о чем свидетельствуют низкие цифры сатурации $\mathrm{O}_{2}$. В связи с этим было принято решении об интубации трахеи. Оперативное вмешательство в объеме наложения временной трахеостомы произвести было невозможно в виду патологического разрастания тканей щитовидной железы, риска кровотечения и возможных гнойно-септических осложнений в раннем послеоперационном периоде. После стабилизации состояния неоднократно предпринимались попытки удаления интубационной трубки, что сопровождалось приступами удушья и риском развития асфиксии. Больной в последующем было предложено мультидисциплинарным консилиумом врачей оперативное лечение в объеме 
тиреоидэктомии и наложении постоянной трахеостомы. Такой объем оперативного вмешательства был обусловлен прежде всего наличием узловых образований в обеих долях щитовидной железы и наличием сформировавшегося стеноза трахеи по типу «песочных» часов. Дополнительным отягощяющим фактором послужило высокий класс сложности интубации трахеи (Mallampati III-IV) и умеренным анестезиолого-операционным риском (II-III степень по МНОАР), что было связано патологический разрастанием тканей щитовидной железы загрудинно с деформацией и изменением контура трахеи. После адекватно проведенной предоперационной подготовки под общим обезболиванием было проведено хирургическое вмешательство в запланированном объеме: тиреоидэктомия, трахеостомия.

Послеоперационная гистология: Диффузно-узловой макрофолликулярный коллоидный зоб. В послеоперационном периоде больная продолжила получать антибактериальную, антикоагулянтную и обезболивающую терапию. Экстубирована на 5 -е сутки после оперативного вмешательства. Приступов удушья зафиксировано не было. Послеоперационная рана зажила первично. На момент выписки трахеостома функционирует. Больная выписана под амбулаторное наблюдение хирурга и эндокринолога по месту жительства. Планируется пла- новое оперативное вмешательство в объеме закрытия трахеостомы через 6 месяцев.

\section{Выво $\Delta$}

1. Наличие сопутствующей патологии на фоне синдрома дыхательной недостаточности обусловливает взаимное отягощение течения обоих заболеваний, повышая риск развития осложнений.

2. Развитие острой дыхательной недостаточности, вызванной тиреоид-ассоциированным компрессионным синдромом является показанием к экстренной или срочной операции.

3. Определение выбора анестезиологического пособия, объема оперативного вмешательства и профилактики до-, интра-, после -операционных осложнений при развитии острой дыхательной недостаточности, вызванной тиреоид-ассоциированным компрессионным синдромом, меняет «привычный» ход действий врача в сторону более радикальных методов лечения, значительно снижающих качество жизни больных

4. Принятие активных мер для предотвращения декомпенсации состояния больных, связанных с развитием тяжелой ДН на фоне тиреоид-ассоциированного компрессионного синдромом являются главными приоритетами в работе врача.

\section{ЛИТЕРАТУРА}

1. Авдеев С. Н. Острая дыхательная недостаточность: основные подходы к диагностике и терапии // Практическая пульмонология. - 2005. - 4.- C. 2529.

2. Биркун А. А. Острая дыхательная недостаточность //Медицина неотложных состояний № 7 (78)-с.102-108-2016 г.].

3. Stefan M.S., Shieh M. S., Pekow P.S., Rothberg M.B, Steingrub J. S., Lagu T., Lindenauer P. K. Epidemiology and outcomes of acute respiratory failure in the United States, 2001 to 2009: a national survey // J. Hosp. Med. - 2013.-8(2). - P. 76-82.

4. World Health Organization — Media Centre [online resource]. Fact sheet No. 310. Available from: URL: http://www. who.int/mediacentre/factsheets/fs310/en/

( ) Вилков Александр Владимирович ( vilkov_a_v@mail.ru ), Голубев Александр Григорьевич, Давыдкин Василий Иванович,

Вельмискина Ирина Васильевна, Пигачев Андрей Вениаминович,

Кимяев Евгений Викторович, Пряников Ильдар Ринатович.

Журнал «Современная наука: актуальные проблемы теории и практики» 